B cells and antibodies in progressive multiple sclerosis: Contribution to neurodegeneration and progression

Peer-reviewed author version

FRAUSSEN, Judith; DE BOCK, Laura \& SOMERS, Veerle (2016) B cells and antibodies in progressive multiple sclerosis: Contribution to neurodegeneration and progression. In: AUTOIMMUNITY REVIEWS, 15(9), p. 896-899.

DOI: 10.1016/j.autrev.2016.07.008

Handle: http://hdl.handle.net/1942/22563 


\section{B cells and antibodies in progressive multiple sclerosis:}

\section{contribution to neurodegeneration and progression}

Judith Fraussen ${ }^{1}$, Laura de Bock ${ }^{1}$, Veerle $\underline{\text { Somers }}^{1}$

${ }^{1}$ Hasselt University, Biomedical Research Institute and Transnationale Universiteit Limburg, School of Life Sciences, Diepenbeek, Belgium

Grant support: J. Fraussen is a postdoctoral fellow of the Fund for Scientific Research (FWO), Flanders.

Corresponding author: Veerle Somers, Hasselt University, Biomedical Research Institute, and Transnationale Universiteit Limburg, School of Life Sciences, Martelarenlaan 42, 3500 Hasselt, Belgium, Tel: +32(0)11269202, Fax: +32(0)11269299, E-mail: veerle.somers@uhasselt.be 


\begin{abstract}
Multiple sclerosis (MS) is a chronic inflammatory disease of the central nervous system (CNS) characterized by demyelination, axonal degeneration and gliosis. The progressive form of MS is an important research topic as not much is known about its underlying mechanisms and no therapy is available. Although progressive MS is traditionally considered to be driven by neurodegeneration, compartmentalized CNS inflammation is currently accepted as one of the driving processes behind neurodegeneration and progression. In this review, the involvement of B cells and antibodies in progressive MS is discussed. The identification of meningeal ectopic B cell follicles in secondary progressive MS (SPMS) patients and the successful use of B cell depleting therapy in primary progressive MS (PPMS) patients have underlined the importance of B cells in progressive MS. Proof is also available for the role of antibodies in neurodegeneration and progression in MS. Here, oligoclonal immunoglobulin M (IgM) production and autoreactive antibodies are described, with a focus on antibodies directed against sperm-associated antigen 16 (SPAG16). Further research into the role of B cells and autoantibodies in MS progression can lead to novel prognostic and theranostic opportunities.
\end{abstract}

Key words: multiple sclerosis, central nervous system, B cells, antibodies, sperm-associated antigen 16

\title{
Take-home messages:
}

- Although current immunomodulatory therapies have not been successful in progressive MS, more evidence is becoming available for the involvement of inflammation, at least in a proportion of progressive MS patients.

- Important proof for the involvement of B cells in progressive MS has come from the finding of ectopic B cell follicles in the meninges of SPMS patients and from clinical trials using B cell depleting therapy in PPMS.

- Oligoclonal lgM bands in the CSF are linked to faster progression into SPMS and to active inflammation in PPMS.

- Anti-SPAG16 antibodies could be a prognostic marker in PPMS, as seropositivity is associated with increased progression index.

- Future research on B cells and autoantibodies in progressive MS could lead to novel opportunities in treatment and prognosis. 


\section{Introduction}

Multiple sclerosis (MS) is a debilitating disease in which chronic inflammation occurs in the central nervous system (CNS), leading to myelin loss, axonal pathology and neurodegeneration [1]. Progressive MS remains one of the greatest challenges in the MS field, which has led to the foundation of the International Progressive MS Alliance, dedicated to accelerating the development of treatment for progressive MS. Gradual disability progression is a major characteristic of progressive MS that occurs from start of the disease in primary progressive MS (PPMS) or following a disease course with alternating periods of relapse and remission (relapsing-remitting MS, RRMS) in secondary progressive MS (SPMS). Both SPMS and PPMS can be designated as active or not active depending on the occurrence of clinical relapses and/or activity on magnetic resonance imaging (MRI), defined by the presence of contrast-enhancing lesions or new and enlarging T2 lesions [2]. At the pathological level, grey and white matter atrophy, axonal loss, cortical demyelination and changes in the normal-appearing white matter (NAWM) contribute to neurodegeneration [3].

B cells are important contributors to the chronic inflammatory processes in MS pathogenesis. Oligoclonal immunoglobulin bands (OCB) are found in the cerebrospinal fluid (CSF) of more than $90 \%$ of MS patients, pointing to an intrathecal antibody production [4]. Various autoantigens have been suggested as targets of these autoantibodies, although specificity and pathologic potential remain controversial $[5,6]$. Clonal B cell proliferation has been noted both in the CNS and in the periphery $[7,8]$. B cells are further implicated in MS pathology by stimulation of pro-inflammatory $T$ cell responses and the production of pro-inflammatory cytokines, including lymphotoxin (LT), tumor necrosis factor alpha (TNF-a) and interleukin$6(\mathrm{IL}-6)[9]$.

As most current immunomodulatory therapies for RRMS did not meet endpoints in trials of progressive MS, neurodegeneration instead of inflammation has traditionally been considered as main driver of progression in MS. However, evidence is now available for the involvement of inflammation in progressive MS. The absence of blood-brain barrier (BBB) leakage in cases of perivascular inflammation in progressive MS has suggested the entrapment of CNS inflammation behind the BBB [10]. Post-mortem brain tissue from different MS subtypes further showed pronounced inflammation in SPMS and PPMS with a positive association between inflammation and axonal injury [11]. In addition, comparable numbers of activated intrathecal B cells and T cells were indicated in progressive MS (SPMS and PPMS) and RRMS patients [12]. In this review, the involvement of $B$ cells and antibodies in inflammation in progressive MS (both SPMS and PPMS) is discussed in more detail (Fig. 1). SPMS and PPMS are discussed together, as it was suggested that both MS subtypes do not have pathophysiologically distinct features [2]. 
Periphery

(1)

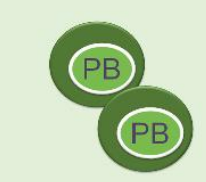

$\uparrow$ plasma blasts

(4)

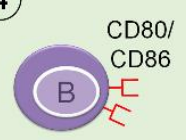

$\uparrow \mathrm{CD} 80 / \mathrm{CD} 86$

expression*
(2)

CD83
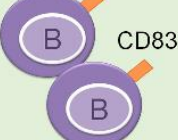

(3) DC-SIGN

(B) DC-SIGN

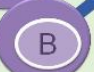

$\uparrow \mathrm{CD} 3^{+} \mathrm{B}$ cells

(5)

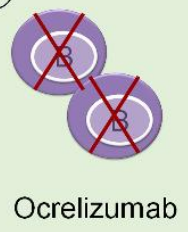

(6)

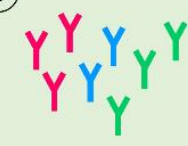

$\uparrow$ autoAbs to:

SPAG16*, neuro-

CNS

(7)

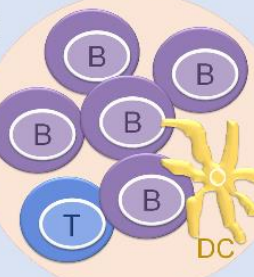

Ectopic follicle*
(8)

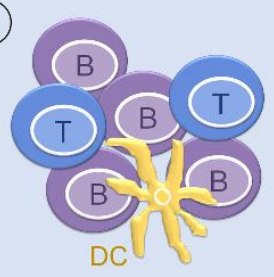

B cell rich cortical lesions

(9)

filament*, GM3

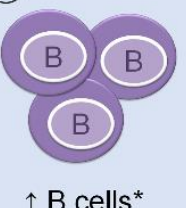

(10)

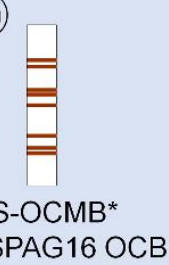

(11)

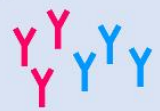

$\uparrow$ Abs to SPAG16, neurofilament

Figure 1. Current proof for the involvement of $B$ cells and antibodies in neurodegeneration and progression. In the peripheral blood of SPMS patients, increased numbers of plasma blasts (1), CD83+ B cells (2) and activated DC-SIGN ${ }^{+}$B cells (3) were present. Elevated B cell CD80/CD86 expression was shown in MS with high neurodegeneration (4). Positive clinical results were obtained using ocrelizumab (5) and increased serum/plasma autoantibodies were found (6). In the CNS, ectopic follicles (7) and B cell rich cortical lesions (8) were identified. Progressive MS CSF demonstrated increased B cell numbers (9), LS-OCMB and anti-SPAG16 OCB (10) together with increased autoantibodies (11). ${ }^{*}$ indicates an association with neurodegeneration or progression. PB: plasma blast, B: B cell, Abs: antibodies, T: T cell, DC: dendritic cell, LS-OCMB: lipid-specific oligoclonal IgM bands

\section{B cells in neurodegeneration and progressive MS}

A first indication for B cell involvement in progressive MS came from the identification of ectopic $B$ cell follicles in the meninges of SPMS patients $[13,14]$. This local B cell proliferation pointed to the sustainment of inflammation in progressive disease. Ectopic B cell follicles were associated with early disease onset, cortical demyelination, microglia activation, loss of neurites and irreversible disability [15]. Further, cortical lesions with B cell rich infiltrates were described, while high B cell to monocyte CSF ratios were associated with more rapid disease progression in SPMS patients [16, 17].

Interestingly, a recent phase III clinical trial of the B cell depleting anti-CD20 monoclonal antibody (mAb) ocrelizumab (ORATORIO) in PPMS met both primary (confirmed disability progression after 12 weeks of treatment) and secondary (confirmed disability progression after 24 weeks of treatment, timed walk, T2 lesion volume and total brain volume) endpoints [18]. As ocrelizumab demonstrated clinical effectiveness, the importance of B cells in inflammation in PPMS has become evident. Moreover, intrathecal rituximab administration in a single SPMS patient led to reduced inflammation and 
neurodegeneration as indicated by reductions in inflammatory markers such as tumor necrosis factor (TNF), interleukin-2 (IL-2) and neurofilament light [19].

More descriptive evidence for the role of $B$ cells in neurodegeneration and progression has come from observation studies. While plasmablasts, DC-SIGN+ B cells and CD83+ B cells were all increased in the peripheral blood of SPMS patients, DC-SIGN+ B cells correlated with disease progression [20]. Thus, activated B cells (DC-SIGN+) and B-T cell interactions (CD83) are involved in SPMS. Further, MS patients with high neurodegeneration showed an increased B cell activation status (elevated CD80 and CD86 expression) compared to MS patients with low neurodegeneration [21].

\section{Antibodies in neurodegeneration and progressive MS}

The occurrence of autoantibodies has been associated with progression and axonal loss in progressive MS. We describe oligoclonal IgM production and autoreactive antibodies, with a focus on anti-SPAG16 antibodies.

\subsection{Intrathecal oligoclonal lgM antibodies}

The finding of oligoclonal IgM bands (OCMB) in the CSF is an unfavorable prognostic marker in MS [22]. These intrathecal IgM antibodies are mostly directed against myelin lipids, preferentially phosphatidylcholine. Patients with lipid-specific OCMB (LS-OCMB) suffered from more aggressive disease with higher relapse rate and increased disability [23]. OCMB in RRMS patients were associated with increased expanded disability status scale (EDSS), progression index and probability to evolve into SPMS [24]. Also the time to conversion to SPMS was lower in LS-OCMB+ MS patients [25]. In PPMS, OCMB were associated with an active inflammatory disease phenotype that could benefit from immunomodulatory treatment [26]. OCMB positivity has further been linked to increased CSF levels of neurofilament light, a marker of neurodegeneration and axonal damage $[27,28]$. Compared with LS-OCMB- MS patients, LS-OCMB+ MS patients presented with a reduced retinal nerve fiber layer (RNFL) thickness, pointing to increased axonal loss [29]. LS-OCMB+ MS patients further showed an increased multiple sclerosis severity score (MSSS), a clinical measure of disease severity. All these studies provide proof for the involvement of lipid-specific lgM antibodies in neurodegeneration and progression.

\subsection{Anti-SPAG16 antibodies}

Sperm-associated antigen 16 (SPAG16) was first identified as an autoantibody target in the CSF of MS patients using a high-throughput cDNA phage display-based approach [30]. Anti-SPAG16 antibodies were increased in the plasma of 21\% of MS patients with $95 \%$ specificity [31]. The pathologic potential of these autoantibodies was demonstrated by the 
identification of SPAG16-specific oligoclonal bands (OCB) in the CSF of MS patients, including progressive MS patients, and increased disease severity when administering anti-SPAG16 antibodies to mice with experimental autoimmune encephalomyelitis (EAE), the animal model of MS. Anti-SPAG16 antibody reactivity was also indicated in the CSF of progressive MS patients (unpublished results). We recently showed that anti-SPAG16 seropositivity was associated with an increased EDSS in MS [32]. Both anti-SPAG16 antibody levels and the proportion of seropositive patients were increased in PPMS patients compared to RRMS and SPMS patients. Interestingly, anti-SPAG16 seropositivity was correlated with an increased progression index in PPMS, as defined by the shorter disease duration and comparable EDSS as seronegative PPMS patients. These findings raised the possibility that disease progression in MS is related to antibody-mediated CNS damage and anti-SPAG16 antibodies could be used as a possible prognostic biomarker in PPMS. SPAG16 expression was found to be upregulated in reactive astrocytes in MS brain lesions and was also expressed in neurons [31]. Astrocytes are becoming increasingly recognized as important players in MS progression. Based on research in fertility and of other SPAG proteins in cancer, SPAG16 could function in the brain in motility, structure, stability, survival and stress-related responses in astrocytes and neurons [33,34]. We hypothesize that proinflammatory cytokines and other inflammatory mediators, such as nitric oxide (NO) and reactive oxygen species (ROS), activate astrocytes in active MS lesions, which results in the upregulation of SPAG16 expression (Fig. 2). We have demonstrated SPAG16 upregulation in primary human astrocytes after in vitro exposure to ciliary neurotrophic factor (CNTF), IL-1 $\beta$ and polyinosinic:polycytidylic acid (Poly I:C), commonly used to activate astrocytes in vitro (unpublished results). After astrocytic damage during CNS inflammation, intracellular SPAG16 is released and anti-SPAG16 antibodies are formed. Astrocyte damage has been shown already early in MS, concomitant with the appearance of perivascular inflammation, and may be an important feature in lesion formation [35]. The formed anti-SPAG16 antibodies can then exert their effector function via complement activation, as evidenced by the membrane attack complex formation in EAE following administration of anti-SPAG16 antibodies and by predominance of the $\lg \mathrm{G} 1$ isotype among anti-SPAG16 antibodies [31].

In order to confirm our findings of anti-SPAG16 antibodies as a possible prognostic biomarker in PPMS, future follow-up studies are needed. Additionally, it would be interesting to investigate whether MS patients with anti-SPAG16 antibodies present with a more "inflammatory" PPMS, with a generally worse disease outcome, and whether these antibodies could be used as a biomarker to determine the treatment approach. Further, it is tempting to speculate that anti-SPAG16 seropositive PPMS patients could benefit from current immunomodulatory therapies. It is also of interest to investigate the relation between anti-SPAG16 antibodies and OCMB or neurofilament light levels. 


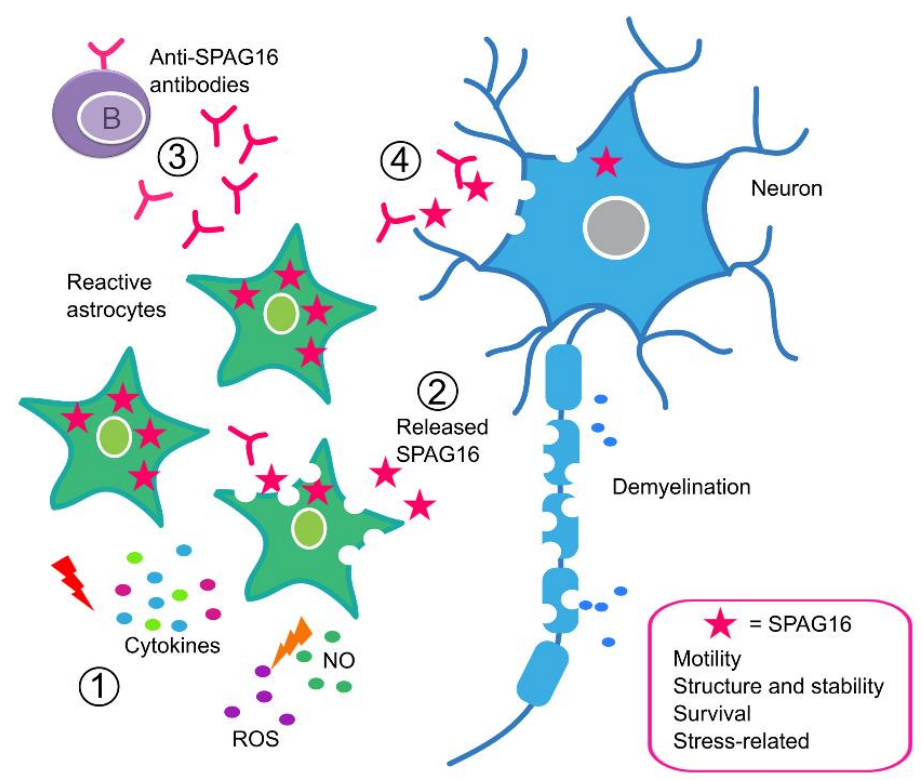

Figure 2. Schematic representation of SPAG16 and anti-SPAG16 antibodies in MS. Proinflammatory cytokines and other inflammatory mediators, such as nitric oxide (NO) and reactive oxygen species (ROS), activate astrocytes and lead to SPAG16 upregulation (1). Damage to astrocytes releases SPAG16 (2) and antibodies against SPAG16 can be formed (3). Finally, anti-SPAG16 antibodies bind their target and mediate damage (4). Possible functions of SPAG16 are shown.

\subsection{Other autoantibodies}

Other autoantibodies that have been associated with neurodegeneration or progression are anti-neurofilament and antiganglioside antibodies. Different studies demonstrated that serum anti-neurofilament light antibodies were elevated in PPMS patients, were produced intrathecally and were associated with neurodegeneration, although another study could not confirm this [22]. Considering anti-ganglioside antibodies, serum antibody levels against GM3 were increased in PPMS patients compared to RRMS patients and healthy and neurological controls [36].

\section{Conclusion}

As no therapy is currently available for the treatment of progressive MS, much effort nowadays goes to research in this area. All available evidence indicates B cells and antibodies as main drivers behind compartmentalized CNS inflammation in progressive MS. Future research that focuses on B cells and autoantibodies could lead to novel opportunities for therapy and prognosis in PPMS and SPMS. By the identification of progressive MS patients with a pronounced inflammatory compound ( $B$ cell and/or antibody involvement), patients that could benefit from current immunomodulatory treatment could be discriminated. Testing for the presence of anti-SPAG16 antibodies could play an important role in future prognostic and theranostic applications of MS. 


\section{References}

[1] Karussis D. The diagnosis of multiple sclerosis and the various related demyelinating syndromes: a critical review. J Autoimmun 2014;48-49:134-142.

[2] Lublin FD, Reingold SC, Cohen JA, Cutter GR, Sorensen PS, Thompson AJ, Wolinsky JS, Balcer LJ, Banwell B, Barkhof F, Bebo B, Jr., Calabresi PA, Clanet M, Comi G, Fox RJ, Freedman MS, Goodman AD, Inglese M, Kappos L, Kieseier BC, Lincoln JA, Lubetzki C, Miller AE, Montalban X, O'Connor PW, Petkau J, Pozzilli C, Rudick RA, Sormani MP, Stuve O, Waubant E, Polman CH. Defining the clinical course of multiple sclerosis: the 2013 revisions. Neurology 2014;83:278-286.

[3] Lassmann H, Bruck W, Lucchinetti CF. The immunopathology of multiple sclerosis: an overview. Brain Pathol 2007;17:210-218.

[4] Cole SR, Beck RW, Moke PS, Kaufman DI, Tourtellotte WW. The predictive value of CSF oligoclonal banding for MS 5 years after optic neuritis. Optic Neuritis Study Group. Neurology 1998;51:885-887.

[5] Fraussen J, Claes N, de Bock L, Somers V. Targets of the humoral autoimmune response in multiple sclerosis. Autoimmun. Rev 2014;13:1126-1137.

[6] Ramanathan S, Dale RC, Brilot F. Anti-MOG antibody: The history, clinical phenotype, and pathogenicity of a serum biomarker for demyelination. Autoimmun Rev 2015.

[7] Stern JN, Yaari G, Vander Heiden JA, Church G, Donahue WF, Hintzen RQ, Huttner AJ, Laman JD, Nagra RM, Nylander A, Pitt D, Ramanan S, Siddiqui BA, Vigneault F, Kleinstein SH, Hafler DA, O'connor KC. B cells populating the multiple sclerosis brain mature in the draining cervical lymph nodes. Sci. Transl. Med 2014;6:248ra107.

[8] Vrolix K, Fraussen J, Losen M, Stevens J, Lazaridis K, Molenaar PC, Somers V, Bracho MA, Le Panse R, Stinissen P, BerrihAknin S, Maessen JG, Van Garsse L, Buurman WA, Tzartos SJ, De Baets MH, Martinez-Martinez P. Clonal heterogeneity of thymic B cells from early-onset myasthenia gravis patients with antibodies against the acetylcholine receptor. J Autoimmun 2014;52:101-112.

[9] Bao Y, Cao X. The immune potential and immunopathology of cytokine-producing B cell subsets: a comprehensive review. J Autoimmun 2014;55:10-23.

[10] Lassmann H. New concepts on progressive multiple sclerosis. Curr Neurol Neurosci Rep 2007;7:239-244.

[11] Frischer JM, Bramow S, Dal-Bianco A, Lucchinetti CF, Rauschka H, Schmidbauer M, Laursen H, Sorensen PS, Lassmann H. The relation between inflammation and neurodegeneration in multiple sclerosis brains. Brain 2009;132:1175-1189.

[12] Komori M, Blake A, Greenwood M, Lin YC, Kosa P, Ghazali D, Winokur P, Natrajan M, Wuest SC, Romm E, Panackal AA, Williamson PR, Wu TX, Bielekova B. Cerebrospinal fluid markers reveal intrathecal inflammation in progressive multiple sclerosis. Annals of Neurology 2015;78:3-20.

[13] Serafini B, Rosicarelli B, Magliozzi R, Stigliano E, Aloisi F. Detection of ectopic B-cell follicles with germinal centers in the meninges of patients with secondary progressive multiple sclerosis. Brain Pathol 2004;14:164-174. 
[14] Howell OW, Reeves CA, Nicholas R, Carassiti D, Radotra B, Gentleman SM, Serafini B, Aloisi F, Roncaroli F, Magliozzi R, Reynolds R. Meningeal inflammation is widespread and linked to cortical pathology in multiple sclerosis. Brain 2011;134:27552771.

[15] Magliozzi R, Howell O, Vora A, Serafini B, Nicholas R, Puopolo M, Reynolds R, Aloisi F. Meningeal B-cell follicles in secondary progressive multiple sclerosis associate with early onset of disease and severe cortical pathology. Brain 2007;130:1089-1104.

[16] Fischer MT, Wimmer I, Hoftberger R, Gerlach S, Haider L, Zrzavy T, Hametner S, Mahad D, Binder CJ, Krumbholz M, Bauer J, Bradl M, Lassmann H. Disease-specific molecular events in cortical multiple sclerosis lesions. Brain 2013;136:1799-1815.

[17] Cepok S, Jacobsen M, Schock S, Omer B, Jaekel S, Boddeker I, Oertel WH, Sommer N, Hemmer B. Patterns of cerebrospinal fluid pathology correlate with disease progression in multiple sclerosis. Brain 2001;124:2169-2176.

[18] Fyfe I. In the news: Ocrelizumab excites ectrims. Nat Rev Neurol 2015;advance online publication.

[19] Studer V, Rossi S, Motta C, Buttari F, Centonze D. Peripheral B cell depletion and central proinflammatory cytokine reduction following repeated intrathecal administration of rituximab in progressive Multiple Sclerosis. J Neuroimmunol 2014;276:229-231.

[20] Romme Christensen J, Bornsen L, Ratzer R, Piehl F, Khademi M, Olsson T, Sorensen PS, Sellebjerg F. Systemic inflammation in progressive multiple sclerosis involves follicular T-helper, Th17- and activated B-cells and correlates with progression. PLoS One 2013;8:e57820.

[21] Comabella M, Canto E, Nurtdinov R, Rio J, Villar LM, Picon C, Castillo J, Fissolo N, Aymerich X, Auger C, Rovira A, Montalban X. MRI phenotypes with high neurodegeneration are associated with peripheral blood B-cell changes. Hum Mol Genet 2016;25:308-316.

[22] Fitzner B, Hecker M, Zettl UK. Molecular biomarkers in cerebrospinal fluid of multiple sclerosis patients. Autoimmun Rev 2015;14:903-913.

[23] Villar LM, Sadaba MC, Roldan E, Masjuan J, Gonzalez-Porque P, Villarrubia N, Espino M, Garcia-Trujillo JA, Bootello A, AlvarezCermeno JC. Intrathecal synthesis of oligoclonal lgM against myelin lipids predicts an aggressive disease course in MS. J. Clin. Invest 2005;115:187-194.

[24] Villar LM, Masjuan J, Gonzalez-Porque P, Plaza J, Sadaba MC, Roldan E, Bootello A, Alvarez-Cermeno JC. Intrathecal IgM synthesis is a prognostic factor in multiple sclerosis. Ann Neurol 2003;53:222-226.

[25] Thangarajh M, Gomez-Rial J, Hedstrom AK, Hillert J, Alvarez-Cermeno JC, Masterman T, Villar LM. Lipid-specific immunoglobulin M in CSF predicts adverse long-term outcome in multiple sclerosis. Mult. Scler 2008;14:1208-1213.

[26] Villar LM, Casanova B, Ouamara N, Comabella M, Jalili F, Leppert D, de Andres C, Izquierdo G, Arroyo R, Avsar T, Lapin SV, Johnson T, Montalban X, Fernandez O, Alvarez-Lafuente R, Masterman D, Garcia-Sanchez MI, Coret F, Siva A, Evdoshenko E, Alvarez-Cermeno JC, Bar-Or A. Immunoglobulin M oligoclonal bands: biomarker of targetable inflammation in primary progressive multiple sclerosis. Ann Neurol 2014;76:231-240. 
[27] Villar LM, Picon C, Costa-Frossard L, Alenda R, Garcia-Caldentey J, Espino M, Muriel A, Alvarez-Cermeno JC. Cerebrospinal fluid immunological biomarkers associated with axonal damage in multiple sclerosis. Eur J Neurol 2015;22:1169-1175.

[28] D'Ambrosio A, Pontecorvo S, Colasanti T, Zamboni S, Francia A, Margutti P. Peripheral blood biomarkers in multiple sclerosis. Autoimmun Rev 2015;14:1097-1110.

[29] Alvarez-Cermeno JC, Munoz-Negrete FJ, Costa-Frossard L, de la Maza SS, Villar LM, Rebolleda G. Intrathecal lipid-specific oligoclonal IgM synthesis associates with retinal axonal loss in multiple sclerosis. J Neurol Sci 2016;360:41-44.

[30] Somers V, Govarts C, Somers K, Hupperts R, Medaer R, Stinissen P. Autoantibody profiling in multiple sclerosis reveals novel antigenic candidates. J. Immunol 2008;180:3957-3963.

[31] de Bock L, Somers K, Fraussen J, Hendriks JJ, van HJ, Rouwette M, Hellings N, Villar LM, Alvarez-Cermeno JC, Espino M, Hupperts R, Jongen P, Damoiseaux J, Verbeek MM, De Deyn PP, D'hooghe M, Van WB, Stinissen P, Somers V. Spermassociated antigen 16 is a novel target of the humoral autoimmune response in multiple sclerosis. J. Immunol 2014;193:21472156.

[32] de Bock L, Fraussen J, Villar LM, Alvarez-Cermeno JC, Van Wijmeersch B, van Pesch V, Stinissen P, Somers V. Anti-SPAG16 antibodies in primary progressive multiple sclerosis are associated with an elevated progression index. Eur J Neurol 2015.

[33] Zhang Z, Kostetskii I, Tang W, Haig-Ladewig L, Sapiro R, Wei Z, Patel AM, Bennett J, Gerton GL, Moss SB, Radice GL, Strauss JF. Deficiency of SPAG16L causes male infertility associated with impaired sperm motility. Biol Reprod 2006;74:751-759.

[34] Silina K, Zayakin P, Kalnina Z, Ivanova L, Meistere I, Endzelins E, Abols A, Stengrevics A, Leja M, Ducena K, Kozirovskis V, Line A. Sperm-associated antigens as targets for cancer immunotherapy: expression pattern and humoral immune response in cancer patients. J Immunother 2011;34:28-44.

[35] Brosnan CF, Raine CS. The astrocyte in multiple sclerosis revisited. Glia 2013;61:453-465.

[36] Sadatipour BT, Greer JM, Pender MP. Increased circulating antiganglioside antibodies in primary and secondary progressive multiple sclerosis. Ann Neurol 1998;44:980-983. 